\title{
Carbonization of Palm Oil Empty Fruit Bunch (EFB) in Hydrothermal Processes to Produce Biochar
}

\author{
Rakhman Sarwono ${ }^{1, *}$, Silvester Tursiloadi ${ }^{1}$ and Kiky Cornelia Sembiring ${ }^{2}$ \\ ${ }^{1}$ Research Centre for Chemistry-Indonesian Institute of Sciences \\ Komplek PUSPIPTEK, Serpong (15314), Tangerang Selatan \\ Phone. 021-7560929, Fax. 021-7560549 \\ ${ }^{2}$ Graduate School of Energy Science, Kyoto University \\ 606-8501 Sakyo-ku, Kyoto, Yoshidahon-cho, Japan \\ *Corresponding author: rach014@lipi.go.id
}

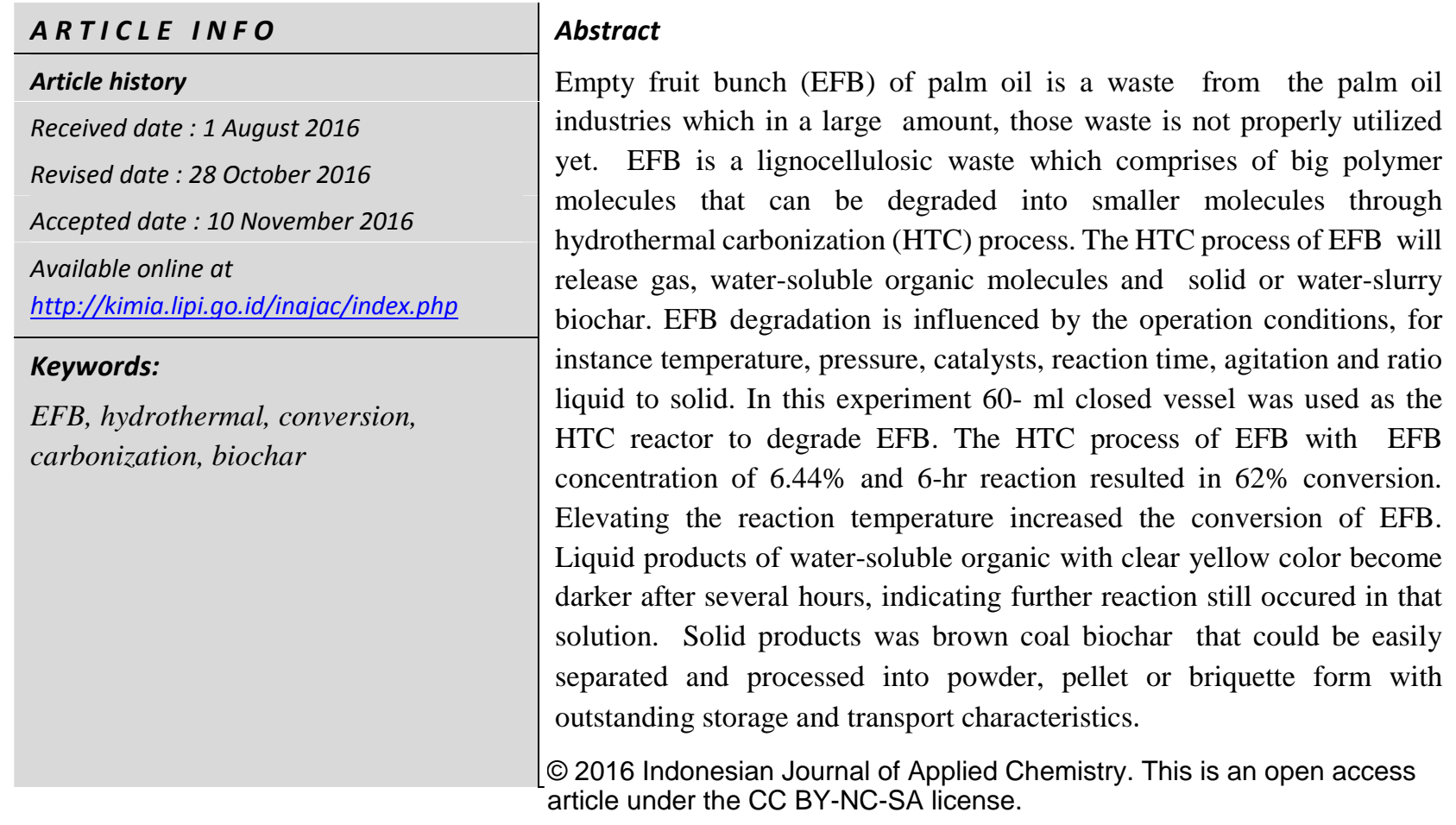

\section{INTRODUCTION}

In recent years, the global issue in the energy field is the combination of increasing energy consumption and steady depletion of fossil fuel resources. This, together with the global environment issues of the appropriate treatment of increasing the production of empty fruit bunch (EFB) has prompted a global research to develop alternative energy and chemicals as well as to reduce $\mathrm{CO}_{2}$ emissions by using renewable energy from biomass and waste $[1,2]$.

The main components of EFB are cellulose, hemicellulose and lignin. EFB comprises around $23 \%$ of the fresh fruit bunch [3]. Even though abundant in quantity, those waste is not fully utilized. Conversion of EFB into carbon, soluble liquid and gas is done through hydrothermal carbonization [4].

There are many types of biomass treatments, for instance, mechanical treatment, biological treatment, and their combination. However, mechanical and biological treatment stage have common problems that they require long time, more than 1 week to 1 month, and created unpleasant smells [5,6]. The hydrothermal treatment is one of the thermochemical processes thattreats waste in high temperature and high pressure water media to upgrade the material in a short time [4,7]. It is one of progressive technologies for converting municipal solid waste (MSW) and biomass into useful energy resources because it can improve the dehydration and drying performance of high 
moisture content biomass as well as upgrade the properties of the fuel produced from MSW.

Hydrothermal treatment has been applied in various fields, such as synthesis and decomposition of organic materials [8]. In recentyears, application of hydrothermal treatment expands to biomass gasification and biomass liquefaction. Nowadays, hydrothermal treatment iss applied in the field of biomass saccharification and one of the efficient techniques.

Hydrothermal technologies are broadly defined as chemical and physical transformations athigh temperature (200 $\left.600^{\circ} \mathrm{C}\right)$, high pressure $(5-40 \mathrm{MPa})$ in a liquid or supercritical water [9]. Water is an excellent medium for intermediate hydrolysis of cellulose and high molecular weight carbohydrates to water-soluble sugars. The primary reaction in the conversion to oil likely involves the formation of low-moleculer weight, water-soluble compounds such as glucose. The sugar is deoxygenated producing high carbon-hydrogen compounds.

Most organic compounds do not react with water under normal conditions. However, at temperatur between $250^{\circ} \mathrm{C}$ and $350^{\circ} \mathrm{C}$, molecules in liquid water undergo chemical reactions. Previously, these reaction were only expected to occur in the presence of strong acid or base, but recent research indicates otherwise [10]. Siskin and Katritzky have shown the geochemistry of the reactivity of organic molecules in hot water [10]. Ester groups, which are bound in to the network of resource structure and serve as crosslinks, although thermally unreactive, are easily cleaved in water at 250$350^{\circ} \mathrm{C}$ [11]. Similarly, benzyl aryl ethers were found to be more susceptible to cleavage under aqueous thermal conditions at $250{ }^{\circ} \mathrm{C}$. Cyclohexyl phenyl compounds with oxygen, sulfur, and nitrogen links are relatively unreactive thermally, but they readily cleave in water at $250{ }^{\circ} \mathrm{C}$ [12].

Hydrothermal carbonization (HTC) is a thermo-chemical process used to convert biomass into a coal-like material with a higher carbon content [13]. It is realized by applying high temperature $\left(180-220^{\circ} \mathrm{C}\right)$ to biomass in presence of water under saturated pressure during several hours. Due to the need for efficient biomass technologies and its particularities and advantages over other conversion processes, HTC is seen as a promising technology to transform wet biomass waste streams into a coal-like product that can be used not only as a renewable combustible or a soil conditioner but also for a wide range of other environmental, electrochemical and catalytic applications [13]. Another advantage is that the substrate can be hygienized during the HTC process. Therefore it can be seen as a potential technology to treat problematic biomass streams like industrial waste, biowaste or sewage sludge.

The conversion of biomass into products with higher carbon contents can take place by means of different thermochemical processes. Pyrolysis is, for example, a process which occurs under high temperature and in the absence of oxygen, and leads to the formation of charcoal [14].

When pyrolysis is carried out in the presence of sub-critical liquid water, at high temperature and pressure, the process is called wet pyrolysis or hydrothermal carbonization (HTC).

Compared to biological treatment methods (like anaerobic digestion or alcoholic fermentation) carbonization of biomass has various advantages. First, the reaction only takes hours compared to days or months needed for biological processes. Furthermore, the high process temperatures eliminate pathogens and inactivate other potential contaminants making the output products sterile and hygienic, as required by some industries, for instance pharmaceuticals [14].

Compared to dry pyrolysis, which requires biomass with low water content (typically wood or crop residues), the main advantage of HTC is that the feedstock does not need to be dried before or during the process, allowing the conversion of organic matters with high water content. HTC can be applied to a wide range of biogenic substrates from feces to municipal biowaste and anaerobic digestate [15]. This process is thus particularly suitable for wet biomass as the energy intensive drying can be avoided. Furthermore, HTC requires lower 
process temperature $\left(180-250^{\circ} \mathrm{C}\right)$ compared to $400^{\circ} \mathrm{C}$ for dry pyrolysis [14].

This makes it an interesting application for the energetic use of organic waste with high moisture content for example in wastewater treatment plants, where the dewatering of fecal sludge for incineration requires a lot of energy.

In addition, HTC is seen as an efficient process for carbon sequestration to mitigate climate change. Compared to other conversion processes that transform carbohydrates into products with higher carbon contents or other burnable fuels, HTC is in fact the most efficient. When biomass is composted, anaerobically digested or fermented, some of the original carbons in the substrate are converted into $\mathrm{CO}_{2} \mathrm{~S}$ and lost to the atmosphere. With HTC however, most of the original carbons present in the substrate stay bound to the final coal product [15].

HTC has high flexibility on the choice of feedstock. In principle, any kind of biomass can be hydrothermally carbonized [17]. Substrates like stabilized and non-stabilized sewage sludge, animal manure, municipal solid waste, agriculture residues and algae are often reported in the literature to be used as input materials [14]. Conclusive experiments have also been carried out using plastics [3] and unsorted municipal solid waste [18]. HTC is typically carried out using a feedstock with water content of $75-90 \%$ or higher. Under $40 \%$, it is unlikely that HTC has many energetic advantage compared with dry pyrolysis [14].

The presence of water in subcriticalcondition at elevated temperature enhances the solvent properties of water and facilitates hydrolysis of organic compounds. During hydrolytic reactions, the presence of water leads to the cleavage of chemical bonds of the biomacromolecules [19]. Hydrolysis has lower activation energy than most of the reaction taking place during dry pyrolysis which leads to lower decomposition temperatures [14]. Under hydrothermal conditions, cellulose is significantly hydrolyzed above approximately $200^{\circ} \mathrm{C}$ [17]. For hemi-cellulose, it occurred at $180-200^{\circ} \mathrm{C}$ and lignin is decomposed between $180-220^{\circ} \mathrm{C}[14]$.
The HTC is mostly described in literature as an exothermic process, during which part of the chemical energy contained in the feedstock is released in form of heat. For this energy to be released and utilized, the activation energy of the reaction has to be overcome. According to Titirici [16], HTC is a spontaneaous process liberating up to a third of the combustion energy stored in the carbohyrates through dehydration. In order to optimize the energy balance of a HTC system, an efficient heat recovery system is necessary. Reduction of heat losses can be achieved by recirculating the hot processing water, which at the same time increases the residence time of the organic compounds dissolved in the water.

\section{EXPERIMENTAL SECTION}

\subsection{Materials}

Palm oil empty fruit bunch (EFB) was used as raw material. It is supplied from palm oil industry at PTPN VIII Malingping, Banten. Distillate water was used as the medium.

\subsection{Methods}

\subsubsection{Experimental procedures}

The equipment used for this experiment is shown in Figure 1.

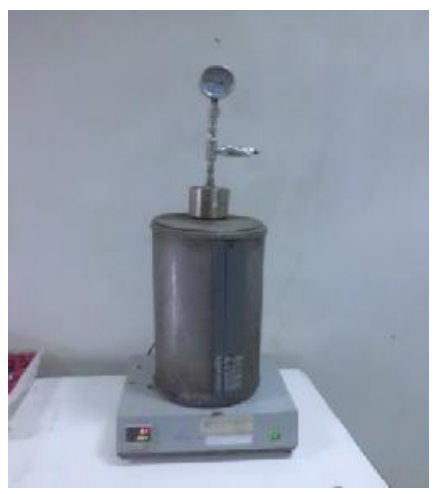

Fig. 1. The equipment scheme of the hydrothermal carbonization

EFB was dried under sun light until the moisture contain reached approximately $12 \%$. EFB was grinded and sieved to obtain particle size of $1-3 \mathrm{~mm}$. A certain amount of EFB was contained in the reactor. $50 \mathrm{ml}$ water was added and than the reactor was sealed to avoid the leaking. Afterward, that reactor was placed on a 
furnace that was equipped with temperature regulator. Reaction occurred in the furnace for a certain time, which is called a reaction time. After the determined reaction time was reached, reactor was pulled out and quenched with tap water to stop the reaction. The solid and liquid products were separated by filtration. The liquid was stored in a bottle while the solid was weighted to know the remaining of the solid parts after degradation. Some solid portions of EFB were converted into gas and water-soluble organic molecules

\subsubsection{Separation procedure}

After the reaction time was reached the reactor was pulled out from the furnace, and then poured with tap water to bring it to room temperature. The gas inside of the furnace was vented out. The liquid and solid were filtered. The solid was washed with the same solvent until the liquid was cleared. The solid was dried at $105^{\circ} \mathrm{C}$ overnight and then quantified until the weight was stable, particularly for the carbon fraction. The liquids were evaporated under vacuum evaporator overnight until the weight did not change (soluble liquid).

Yield of bio - oil $=\frac{\mathrm{M} \text { o b }-\mathrm{o}}{\mathrm{m} \text { o } \mathrm{E}} \times 100 \% \ldots \ldots(1)$

Yield of carbon $=\frac{\mathrm{M} \text { o } \mathrm{c}}{\mathrm{m} \text { o } \mathrm{E}} \times 100 \%$

Conversion rate $=100 \mathrm{wt} \%$ - Yield of carbon

\subsection{Analysis}

\subsubsection{TG-DTA analysis}

The raw material, EFB, was analyzed using thermal analyzer LINSEIS STA Platinum series attemperature range of $150-1750^{\circ} \mathrm{C}$. The equipment was equipped with TG, TG-DTA and TG-DSC sensors.

2.3.2.Elemental and higher heating value (HHV) analysis.

Elements of EFB and biochar were analyzed using Elemental Analyzer (LECO CHN 628).

\section{RESULTS AND DISCUSSION}

The TG-DTA profile of EFB was shown in Figure 2. The EFB has broad endothermic peak with weight losses about $12.2 \%$ at $100^{\circ} \mathrm{C}$. This weight losses accompanied by a broad endothermic peak, can be attributed to the evaporation of the water. A sharp exothermic peak and weight losses about $50.9 \%$ at $300{ }^{\circ} \mathrm{C}$ were observed. Those weight losses accompanied by a sharp exothermic peak can be attributed to the combustion of organic compounds. Also a sharp exothermic peak and a weight drastically loss about $36.9 \%$ at $800^{\circ} \mathrm{C}$ were observed. Those weight losses accompanied by a sharp exothermic peak can be attributed to the combustion of all organic compounds of EFB.

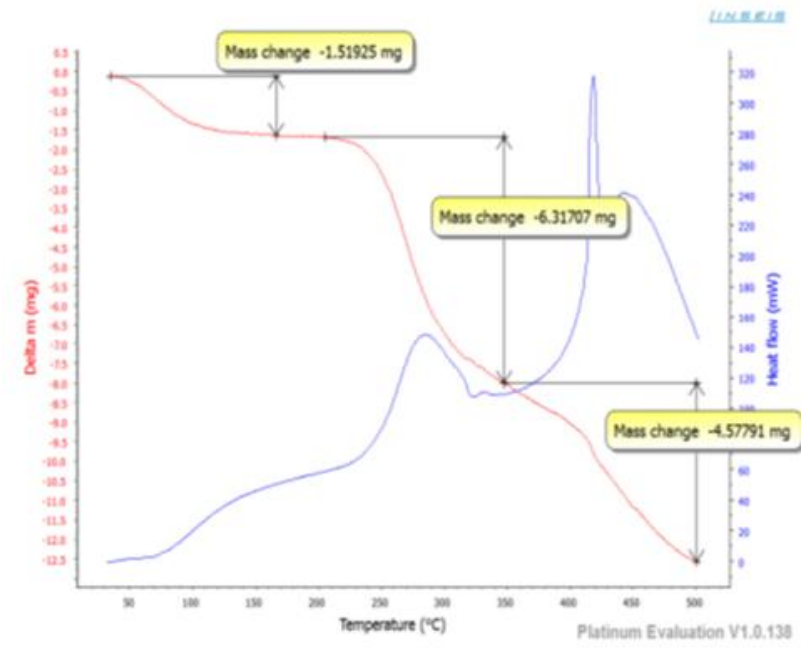

Fig. 2. The thermal analysis of EFB.

The elemental analysis and higher heating value (HHV) were done to analysis the EFB and biochar product from the HTC, as shown in Table 1. The carbon content and the HHV of biochar were higher than the raw material of EFB. The elemental of $\mathrm{C}, \mathrm{H}, \mathrm{N}$, and $\mathrm{O}$ were reduced in biochar content. It is indicated that the degradation of EFB occurs in HTC process.

Table 1. The EFB and biochar elements and HHV

\begin{tabular}{ccc}
\hline Elements & EFB & Biochar \\
\hline $\mathbf{C}(\boldsymbol{\%})$ & 43.84 & 55.22 \\
$\mathbf{H}(\boldsymbol{\%})$ & 6.15 & 5.73 \\
$\mathbf{N}(\boldsymbol{\%})$ & 1.43 & 1.35 \\
$\mathbf{O}(\boldsymbol{\%})$ & 48.58 & 37.69 \\
$\mathbf{H H V}(\mathbf{M J} / \mathbf{K g})$ & 14.94 & 20.13
\end{tabular}


The HTC process was able to degrade the EFB into three fraction, including gas, water soluble, and biochar. Reaction take place in HTC process involved hydrolisis, liquefaction, dehydration, deoksigenation, polimerization and hydrogenation [20].

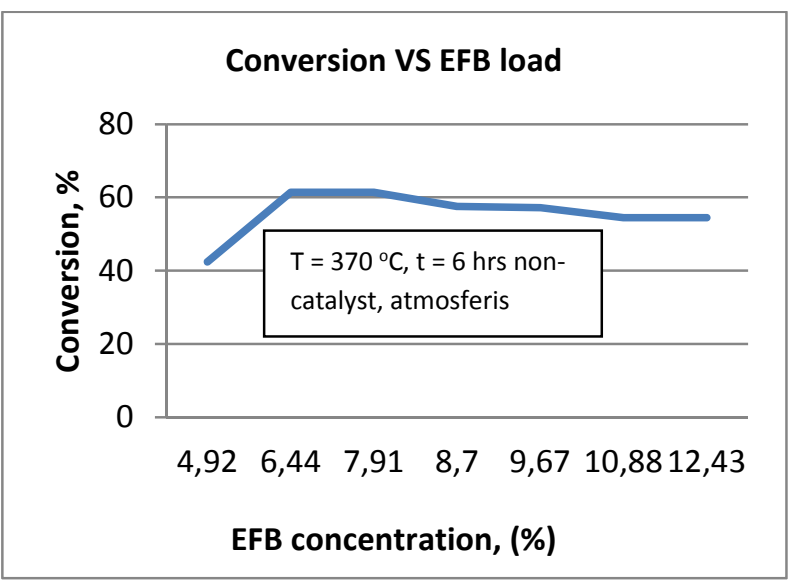

Fig. 3. The conversion in different EFB concentration.

The solid load is the ratio of biomass EFB to water. The biomass should be completely covered with water allowing the reactions take places. As shown in figure 3, the maximum load of EFB $(6.44 \%)$ resulted the highest conversion rate of $62 \%$, by increasing the EFB loading the conversion is slightly decreased.

The solid load is the ratio of biomass to water. A high solid load can be obtained in a lower overall residence time, by increasing the rate at which the concentration of monomers is raising, which allows the polymerization to start earlier [17].

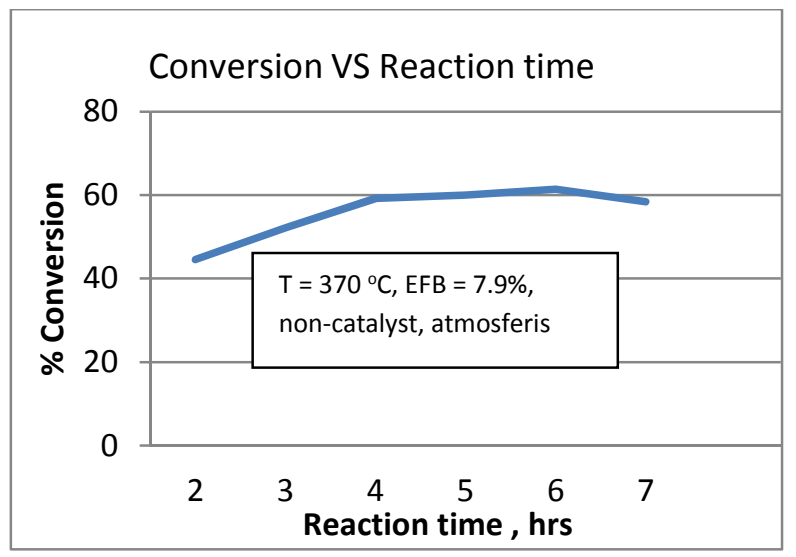

Fig. 4. The conversion of EFB in different reaction time.
Exact residence time cannot be given since reaction rate remained unknown but typical residence time varied from 1 and 72 hours. Experiments with short residence time less than an hour have been carried out and also resulted in a significant increase of heating value of the HTC-char produced [17].

The influenced of residence time to the degradation rate of EFB was shown in Figure 4. The residence time of 6 hours has higher conversion rate, about of $62 \%$, even though the conversion just slightly change after residence time of 4 hours. It meant that increasing residence time do not increase the conversion of EFB significantly. In economic point of view, increasing the residence time will increase the energy cost.

Temperature seems to be the process parameter that has the highest influence on the products characteristics. Higher temperature lead to higher reactions rates, and have a decisive influence on the number biomass compounds that can be hydrolyzed. Substantial hydrolysis starts at a temperature about $180{ }^{\circ} \mathrm{C}$. Both high temperatures and longer residence times increase reaction severity. The higher the reaction severity, the higher the carbon content of the HTC-char could be produced [17]. As shown in figure 5, increasing the temperature will increase the EFB conversion.

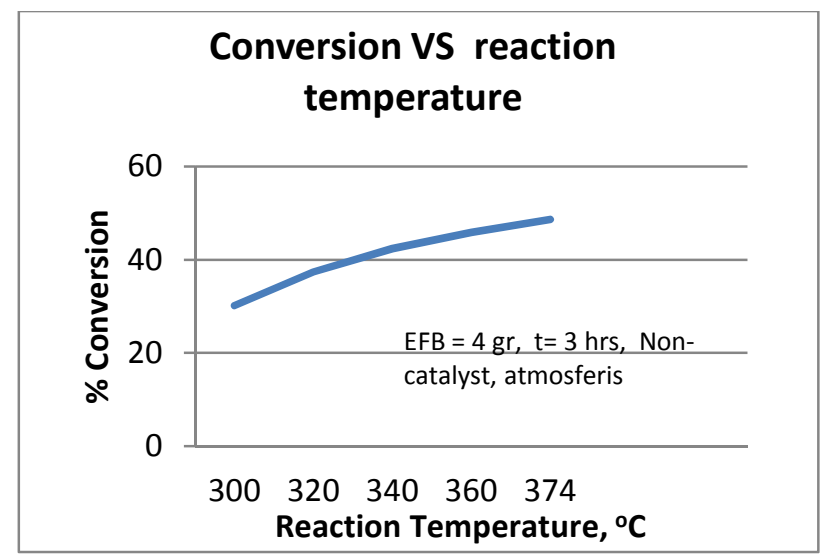

Fig. 5. The conversion of EFB in different reaction temperature.

The high-temperature HTC process proceeds between $300-800^{\circ} \mathrm{C}$, and therefore is clearly beyond the stability of standard organic compounds. Reactive gases and carbon fragments are to be expected from thermolysis. 
The low-temperature HTC process performs below $300^{\circ} \mathrm{C}$, and functional carbonaceous materials can be produced according to dehydration and polymerization schemes. The low-temperature HTC process is presumably close to natural coalification [21]. Softer materials biomass were treated by lowTemperature HTC.

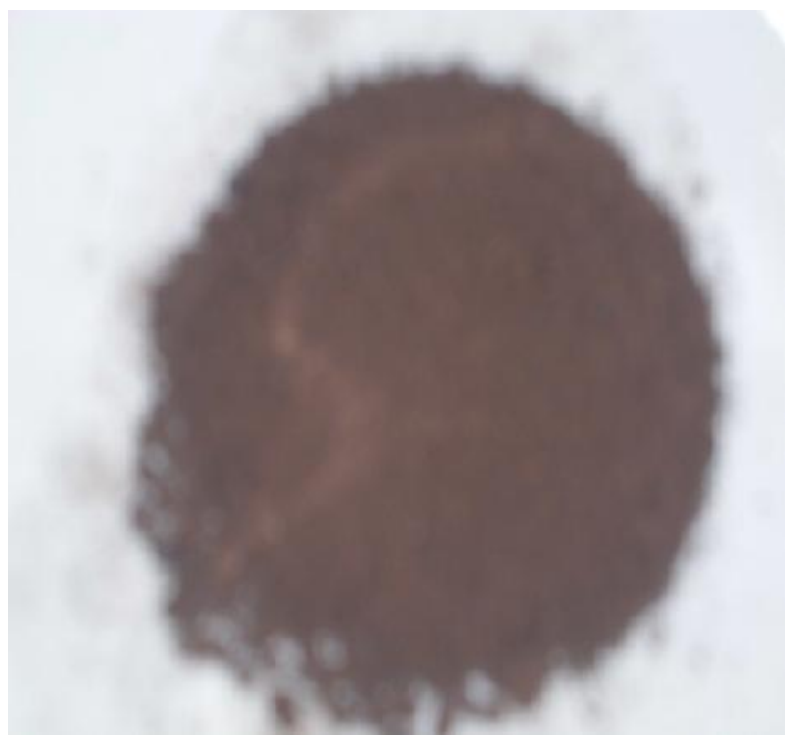

Fig. 6. Brown color of biochar produced from hydrothermal carbonization.

The solid product has the same color like brown coal or HTC-coal. It was separated from the liquid by filtration. This was resulted from the dehydration and decarboxylation process during HTC processes, as shown in figure 6 . The EFB has moisture content of $13 \%$, volatile content of $74 \%$, and fixed carbon content of less than $10 \%$. After carbonization fixed carbon increase to $30 \%$. The HTC-coal increase the carbon content and can be further formed into pellet, granule or briquette which increase the handling and storage characteristics.

HTC has been mostly applied and studied on a limited number of feedstocks, ranging from pure substances to slightly more complex biomass [18], such as woods. Feedstock did not significantly affected the chemical composition of the biochars [22].

EFB is likely more complicated compound than other woods.

The solid product is looked-like brown coal in coloror HTC-coal, is separated from the liquid by filtration. This results from the dehydration and decarboxylation process during HTC processes, as shown in figure 5. The EFB has moisture content of $13 \%$,

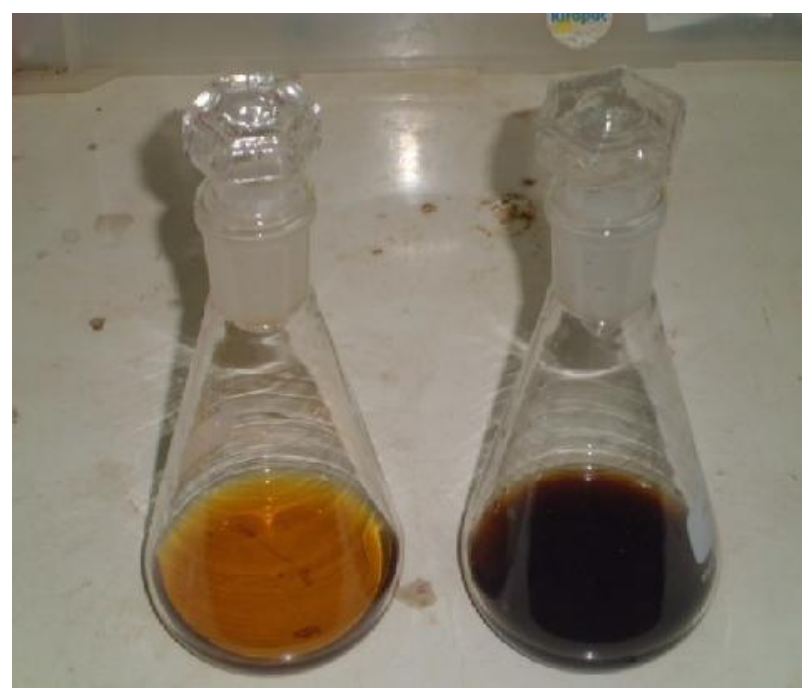

Fig. 7. Liquid products from hydrothermal carbonization.

For further economic development, biochar with excellent transport properties and its possibility to be exported to the world's energy market can provide a stable and reliable demand in many countries, which create an important incentive and market access in many areas

Liquid products as shown in figure 7 indicated that at first the color of the liquid is clear yellow, but after several hours the color become darker. It is proposed that at the early stage of hydrothermal treatment, biomass was oxidized and decomposed to water-soluble fragments and with the storing time, the soluble products were transformed to insoluble products by recondensation reaction [23]. The dark color indicated that there was a chemical reaction in the higher and insoluble fragments occured after separating the slurry.

\section{CONCLUSION}

The HTC of EFB resulted gas, organic water soluble and biochar as solid product or biochar-water-slurry. Biochar-water-slurry was separated by filtering. It aimed to separate organic water soluble with biochar as solid residue. Meanwhile, gas was left out to the 
atmosphere. The HTC-coal fraction can easily be separated from the slurry. The carbon content of the fixed carbon increased from 10\% in raw material into $30 \%$ in the biochar. The biochar can be proceeded further to pellet or briquette form which will increase the storage and handling characteristics.

The HTC process resulted the conversion of solid into gas and water soluble in many variables of operation. The EFB concentration of $6.44 \%$ resulted the higher conversion of $62 \%$ for reaction time of 6 hours. Temperature operation seems to be the most important operating conditions that has great influence to the conversion of EFB.

At first, the color of the liquid product of organic water soluble is clear yellow, however, it become darker after several hours, its seem that further chemical reaction still occur into higher fragments insoluble water.

\section{REFERENCES}

[1]. Y. Kuzuhara.(2005). Biomass Nippon strategy-why "biomass Nippon" now? Biomass and Bioenergy, vol.29, pp. 331335.

[2]. P.E. Alexander.(2010). Technoeconomic aspecs of alternative municipla solid wastes treatment methods. Waste Management, vol.30,pp. 707-118.

[3]. M.S. Subronto. (2015). Penggunaan Aneka Ragam Produk Kalapa Sawit untuk meningkatkan Nilai Tambah Industri Kelapa Sawit (bag. 1). Sawit Indonesia. Edisi 5 Februari 2015.

[4]. A. Funke, F. Ziegler. (2010). Hydrothermal carbonization of biomass: a summary and discussion of chemical mechanisms for process engineering. Biofpr. 4, 160-177.

[5]. R. Barrena, G. Imporzano, S. Ponsa, T. Gea, A. Artola,F. Vazquez, A.Sanchez, and F. Adani. (2009). "In search of a reliable technique for the determination of the biological stability of the organic matter in the mechanical-biological treated waste". J.Harzadous Materials, vol. 162, pp. 1062-1072.

[6]. C. Serrano-Ruiz, D.J.Braden, R.M.West, and J.A. Dumesic. (2010). Conversion of cellulose to hydrocarbon fuel by progressive removal of oxygen. Applied Catal. B: Environmental,vol.100,pp. 184189.

[7]. G. Luo, X. Cheng, W. Shi,P.J.Strong, H.Wang, and W. Ni. (2011). Respone surface analysis of the water: feed ration influence of hydrothermal recovery from biomass. Waste Management, vol.31, pp. 438-444.

[8]. T. Minowa, F. Zhen, and T.Ogi. (1999). Liquefaction of cellulose in hotcompressed water using sodium carbonate: production distribution at different reaction temperature. J.Chem.Eng.Jpn. 30:186-190.

[9]. G. Brunner. (2009). Near critical and supercritical water. Part I. Hydrolytic and hydrothermal processes. The Journal of Supercritical Fluids, 47: 373-381.

[10]. A.A. Peterson, F. Vogel, R.P.Russel, P. Lachance, M.Froling, M.J.Jr.Antal, and J.W. Tester. (2008). Thermochemical biofuel production in hydrothermal media: A Review of sub- and supercritical water technologies. Energy Environ.Sci. 1: 3265.

[11]. M.Siskin, and A. Katritzky. (1991). Reactivity of organic compounds in hot water: Geochemical and technological implications. Science, 254: 231-237.

[12]. M. Siskin, G.Brons, S.Vaughn, A. Katritzky, and M. Balasubramanian. $\left(1990^{\mathrm{a}}\right)$. Aqueous organic chemistry.3.Aquathermolysis: Reactivity of ethers and esthers. Energy and fuels, 4: 488-492.

[13]. T.D. Matson, K. Barta, A.V. Iretskii, and P.C. Ford, (2011). One-Pot Catalytic Conversin of cellulose and of woody biomass solid to Liquid Fuels. J.The American Chemical Society (JACS). 133:14090 - 14097 .

[14]. B. Weber, E.A. Stadlbauer,S. Eichenauer, C. Kock, K. Albert, M. Kramer, and D.Steffens.(2013). Chemical Nature of Carbonaceous Materials from biomass by Hydrothermal Carbonization and low temperature conversion. J. Biobased mat.Bioenergy. vol.7, No. 3: 367 - 375.

[15]. M. Siskin, G. Brons, A. Katritzky, and R. Murugan. $\left(1990^{\mathrm{b}}\right)$. Aqueous organic 
chemistry.2. Cross-linkedc cyclohexyl ohenyl compounds. Energy and fuels, 4: 482-488.

[16]. J.A. Libra, K.S.Ro, C. Kammann, A. Funke, N. Berger, Y. Neubauer,MM.Titirici, C. Fuhner, O. Bens, K. Emmerich. (2011), Hydrothermal carbonization of biomass residuals: a comparative review of the chemistry, processes and applications of wet and dry pyrolysis.s.1.Biofuels,2(1), 89-124.

[17]. M-M. Titirici. (2007). A Direct Synthesis of Mesoporous Carbon with Bicontinuous Pore Morphology from Crude Plant Material by Hydrothermal Carbonization.s.1. Chem. Mater. 19, 42054212.

[18]. N.D. Berge, K.S. Ro, J. Mao,J.R. Flora,M.A. Chappell, S. Bae.(2011). Hydrothermal Carbonization of Municipal Waste Stream.s.1.Environ.Sci.Technol.45, 5696-5703.

[19]. H-J. Huang, X-Z. Yuan, B-T. Li, Y-D. Xiao, and G-M. Zeng, (2014). Thermochemical Liquefaction characteristic of sewage sludge in different organic solvents. J.Analytical and Applied Pyrolysis. 109:176 - 184 .

[20]. C-h., Zhou, X., Xia, C-X., Lin, D-S., Tong and J. Beltramini, (2011). Catalytic conversion of lignocellulosic biomass to fine chemicals and fuels. Chem.Soc.Rev., 40, $5588-5617$.

[21]. B. Hu, K. Wang, L. Wu, S-H. Yu, M. Antonietti, and M-M. Titirici.(2010), Engineering Carbon Materials from the Hydrothermal Carbonization Process of Biomass. Adv.Mater.,22:813-828.

[22]. K. Wiedner, C. Naisse, C. Rumpel, A. Pozzi, P. Wieczorek, B. Glaser. (2013). Chemical modification of biomass residues duringhydrothermal carbonization-What makesthe difference, temperature orfeedstock?. Organic Geochemistry, 54:91-100.

[23]. O. Bobleter, (1994). Hydrothermal degradation of polymers derived from plants. Prog.Polym.Sci. 19,5: 797-841. 